5 Deckert T, Poulsen JE, Larsen M. Prognosis of diabetics with diabetes onset before the age of thirty-one. II. Factors influencing the prognosis. Diabetologia 1978;14:371-7.

- Oakley WG, Pyke DA, Tattersall RB, Watkins PJ. Long-term diabetes. A clinical study of 92 patients after 40 years. $Q \mathcal{F}$ Med $1974 ; 43: 145-56$.

7 Fajans SS, Cloutier MC, Crowther RL. Clinical and etiologic heterogeneity of idiopathic diabetes mellitus. Diabetes $1978 ; 27: 1112-25$.

${ }^{8}$ Leslie RDG, Barnett AH, Pyke DA. Chlorpropamide alcohol flushing and diabetic retinopathy. Lancet $1979 ; \mathrm{i}: 997-9$.

- Barnett AH, Pyke DA. Chlorpropamide-alcohol flushing and large-vessel disease in non-insulin-dependent diabetes. $\mathrm{Br} \mathrm{Med} \mathcal{F} 1980 ; 281: 261-2$.

10 Barnett AH, Leslie RDG, Pyke DA. Chlorpropamide-alcohol flushing and proteinuria in non-insulin-dependent diabetics. $\mathrm{Br} M e d \mathcal{F} 1981 ; 282$ : 522-3.

${ }^{11}$ Leslie RDG, Pyke DA. Chlorpropamide-alcohol flushing: a dominantly inherited trait associated with diabetes. $\mathrm{Br} M e d \mathcal{F} 1978$;ii:1519-21.

12 Leslie RDG, Pyke DA. Identical twins and diabetic retinopathy. Diabetes $1980 ; 29$, suppl $2: 229$.

13 Cudworth AG, Bettazzo CF, Doniach D. Genetic and immunological factors in type I diabetes. In: Irvine WJ, ed. Immunology of diabetes. Edinburgh: Teviot Publications, 1980:67-99.

${ }^{14}$ Gray RS, Clarke BF. Comparison of retinopathy in insulin-dependent diabetics with or without thyroid disease. Br Med f 1979;i :590.

15 Goodkin G. Mortality factors in diabetes. A 20 year mortality study. Fournal of Occupational Medicine 1975;17:716-21.

${ }^{16}$ Pell S, D'Alonzo CA. Factors associated with long-term survival of diabetics. FAMA 1970;214:1833-40.

17 Mogensen CE. Progression of nephropathy in long-term diabetics with proteinuria and effect of initial anti-hypertensive treatment. Scand $\mathcal{F}$ Clin Lab Invest 1976 ;36:383-8.

18 Martin FIR, Warne GL. Factors influencing the prognosis of vascular disease in insulin-deficient diabetics of long duration. A seven-year follow-up. Metabolism 1975;24:1-9.

19 Christiansen JS, Nerup J. Smoking and diabetic nephropathy. Lancet $1978 ; \mathrm{i}: 605$.

20 Barnes AJ, Locke P, Soudder PR, Dormandy TL, Dormandy JA, Slack J. Is hyperviscosity a treatable component of diabetic microcirculatory disease ? Lancet 1977; ii :789-81.

21 Fuller JH, Keen H, Jarrett RJ, et al. Haemostatic variables associated with diabetes and its complications. $B r$ Med $\mathcal{F} 1979$;ii:964-6.

${ }^{22}$ Dimario U, Iavicoli M, Andreani D. Circulating immune complexes in diabetes. Diabetologia 1980;19:89-92.

${ }^{23}$ Andersen OO. Anti-insulin-antibodies and late diabetic complications. Acta Endocrinol (Copenh) 1976;83:329-40.

\section{Immersion or drowning?}

To the man in the street, the novelist, and perhaps to many doctors, a body dragged from the water is obviously drowned, but this is far from the truth. Firstly, the victim may not have drowned and, even if he has, it may be impossible to provewhich may have profound legal consequences.

Many events may end with a corpse in the water. Natural sudden death on a canal bank or quayside is not unknown. Apart from natural disease, a person may be attacked and thrown into nearby water or may be brought there for clandestine disposal after homicide elsewhere. Transportation accidents-vehicular, marine, and aviation-may result in the already-dead landing in water. Next, victims may enter the water alive but die of causes other than drowning. Rapid death may occur, before there is time to drown, from trauma from hitting rocks, bridges, river beds, and the bottoms of swimming baths.

Even when death is caused by immersion this is by no means synonymous with classical drowning. Sudden cardiac arrest may occur as the victim enters the water, before any fluid is aspirated into the air passages. Many such cases have been recorded in seamen returning to their ships on cold nights after an evening's drinking. Such a man may miss the gangway and fall into the dock, and though rescued quickly he may be dead, with no evidence of drowning found at necropsy. Alcohol appears to increase the risk of this type of sudden death, ${ }^{1}$ possibly by flushing the skin and increasing the shock of immersion in icy water. Emotional states have also been blamed as a sensitising factor. The entry of cold water into the nasal passages and larynx is another possible trigger for what used to be termed vagal inhibition and is now labelled reflex cardiac arrest.

Finally, there is actual drowning itself, but even here diagnostic difficulties abound. The older forensic textbooks described froth at the mouth and nostrils and filling of the air passages. The lungs were heavy, waterlogged, and overdistended. These appearances are often absent. The condition of "dry-lung drowning" is common, where no excess fluid is seen in the air passages or lungs at necropsy. In fact, there may be nothing obvious at necropsy apart from non-specific signs of immersion. The difficulties presented by drowned bodies are often compounded by a considerable degree of postmortem decomposition, which obscures any classical signs, even if they were originally present. Sinking of the body, its movement in currents and tides, and the sometimes remote locale, may all delay recovery of the body until putrefaction is far advanced, making a diagnosis on pathological grounds quite impossible.

These problems have led pathologists to devise techniques that might improve their ability to confirm a presumptive diagnosis of drowning. Only one has been relatively successful and even that is controversial. Many promising ideas have been completely discredited by critical review. These depended on the premise that in drowning fluid and electrolytes are transferred across the respiratory interface. Gettler's test purported to prove drowning by measuring the chloride content of plasma in both the right and left cavities of the heart. In theory the massive absorption of water in fresh-water drowning should appreciably dilute the electrolyte on the left side of the heart. Unfortunately, the theory was not borne out in practice. Postmortem diffusion of electrolytes ruined any chance of picking out a significant difference in atrial blood samples, even when the body was examined soon after death. Similar tests using magnesium and other ions as markers were equally unsuccessful.

The only method that is still advocated depends on the recovery of diatoms from the body. Diatoms are unicellular algae with a siliceous shell found in both fresh and salt water; they have many varied shapes, some species being specific for a particular environment. The rationale of the test for drowning depends on the aspiration of diatom-containing water into the lungs. This can occur passively in a dead body falling into water, but the diatoms would not then proceed further than the lungs. If the victim were alive in the water, however, large numbers of diatoms would penetrate the alveolar walls and be carried by the blood stream to distant organs. At necropsy, with strict safeguards against contamination, tissues such as bone marrow, kidney, liver, or even blood itself can be sampled and subject to acid digestion, which will allow the diatoms to be recovered and identified under the microscope.

The test is attractive in theory, but some critics have been doubtful about its reliability. A recent review ${ }^{2}$ from the Home Office Forensic Central Research Establishment at Aldermaston included some foreign contributions not previously available to English readers. The main criticism of the diatom test is that the plankton may also be found in control tissues from necropsies on non-drowned bodies. Controversy continues about the frequency and quantity of this spurious contamination. Should the consensus of opinion finally show that diatoms cannot reliably be stated to have come from aspirated water then this attractive technique becomes of little value. 
Diatoms can appear in the tissues, both from ingestion and from inhalation, and non-drowned cadavers in Berlin have been found to contain marine diatoms. Monkeys from dry, dusty areas may have heavy diatom loads in their lungs. The wrappers of cheap cigars contain numerous diatoms introduced in processing, and these can survive the burning process to be inhaled or swallowed. Experimental work on animals shows that inhaled dust can appear in the tissues, an obvious access route for airborne diatoms. Perhaps the most striking finding of some German workers was that diatoms could be recovered from the tissues of stillborn and premature babies.

Nevertheless, some forensic pathologists, notably in Belgium, where much pioneer work has been done, firmly believe in the reliability of the diatom test. Possibly the matter may be resolved by a quantitative measurement of diatom penetration. Meanwhile, the pathologist must continue to accept further frustration in trying to interpret the findingsor very often, the lack of findings-in many of his immersed bodies.

\footnotetext{
1 Anonymous. Drinking and drowning. $\mathrm{Br} \mathrm{Med} \mathcal{F} 1979 ; \mathrm{i}: 70-1$.

2 Peabody AJ. Diatoms and drowning-a review. Med Sci Law 1980;20: 254-61.
}

\section{Occupational disease and the kidney}

The kidney is a major organ for elimination of foreign substances, and their concentrations in the kidney are frequently far above those in other tissues. Yet, despite its highly active metabolism, the kidney is surprisingly rarely damaged by these potentially toxic compounds, which make only a small contribution to the incidence of tubular damage and renal failure.

Lead, cadmium, mercury, and other heavy metals can all cause tubular and glomerular damage. Stringent regulations on exposure to these metals are enforced in the industrial environment, so that in Britain clinical toxicity is usually due to the results of accidents and misunderstandings rather than to continuous uncontrolled exposure.

More controversial is the part, if any, played by solvents in the development of renal disease. Carbon tetrachloride (still used as an industrial and laboratory solvent) can certainly cause renal tubular damage and even changes suggestive of membranous glomerulonephritis when ingested in large quantities. ${ }^{12}$ Possibly the damage is due to a reactive metabolite such as that which causes hepatic damage. Inhalation of the solvents found in glue and cleaning fluids may contribute to the pathogenesis of crescentic glomerulonephritis. The solvent may induce a change in the alveolar basement membrane, causing formation of anti-basement membrane antibodies, which in turn cross-react with glomerular basement membrane antigens. ${ }^{34}$ Sniffing toluene has even been implicated in the formation of renal stones. ${ }^{5}$ Most of the reported cases of kidney damage have been in patients who inhaled large doses over a short period. Far less is known of the consequences of chronic exposure to smaller amounts.

Some of the commonly used pesticides, including $2,4-\mathrm{D}^{6}$ and paraquat, ${ }^{7}$ cause renal damage in animals and in man when taken in overdosage, but once again there is no evidence that these substances cause damage in man at normal levels of exposure. Recently nephrotoxicity has been reported from inhalation of silica dust. The lesions consist of tubular damage with interstitial fibrosis probably arising as a direct effect of local accumulation. ${ }^{8}$

Often much of the evidence cited when assessing the nephrotoxicity of a particular substance is epidemiological and thus circumstantial. Frequently it is supported with studies in animals which are often of doubtful relevance with respect to species variation and dosing schedules. Better evidence may, however, be difficult to obtain. Many years were needed for analgesic abuse to be recognised as a cause of chronic renal failure, and acceptance was not helped by confusion among some pathologists between pyelonephritis and necrotising papillitis. Environmental toxins may yet prove to be among the causes of some pathologically defined renal diseases which are still of unknown aetiology.

1 Zimina LN, Agapova LS. Morphological alterations in the kidneys due to carbon tetrachloride poisoning. Arkh Patol 1980;42, 3:15-21.

2 Zimmerman SW, Norbach DH. Nephrotoxic effects of long-term carbon tetrachloride administration in rats. Arch Pathol 1980;104, 2:94-9.

${ }^{3}$ Kleinknecht D, Morel-Maroger L, Callard P, Adhémar JP, Mahieu P. Antiglomerular basement membrane nephritis after solvent exposure. Arch Intern Med 1980;140:230-2.

4 Beirne GJ, Brennan JT. Glomerulonephritis associated with hydrocarbon solvents. Mediated by antiglomerular basement membrane antibody. Arch Environ Health 1972;25:365-9.

${ }^{5}$ Kroeger RM, Moore RJ, Lehman TH, Giesy JD, Skeeters CE. Recurren urinary calculi associated with toluene sniffing. F Urol 1980;123:89-91.

6 Wells WDE, Wright N, Yeoman WB. Clinical features and treatment of poisoning with 2,4-D and Mecoprop. Clin Toxicol 1981;18:273-5.

${ }^{7}$ Proudfoot AT, Stewart MS, Levitt T, Widdop B. Paraquat poisoning: significance of plasma-paraquat concentrations. Lancet 1979 ;ii:330-2.

${ }^{8}$ Hauglustaine B, Van Damme B, Daenens P, Michielsen P. Silicon nephropathy: a possible occupational hazard. Nephron $1980 ; 26: 219-24$.

\section{Physical methods of prophylaxis against venous thrombosis}

Ten years' research has given surgeons a wide choice of treatments claimed to diminish the risk of postoperative thromboembolism. A recent poll by Morris $^{1}$ of surgical policies of prophylaxis in Britain showed some surprising results. Among general and orthopaedic surgeons (response rate $>70 \%$ ) the use of routine prophylaxis was inversely related to the risk of thromboembolism: $38 \%$ for hip fractures, $52 \%$ for hip replacements, and $62 \%$ for major abdominal and thoracic operations. Morris argued that this willingness among surgeons to take risks on behalf of their patients was justifiable on the grounds that for no prophylactic agent has the very large trial been done on many thousands of patients that would be needed to show a benefit in overall survival, as distinct from preventing deaths from embolism. This may be a valid academic argument but it should find little favour with the surgeon who is about to operate on a patient known to be at high risk of thromboembolism.

The poll also showed that relatively little use was made of physical methods of prophylaxis, such as elastic compression, electrical stimulation, pedalling devices, or pneumatic compression. Either singly or in combination with pharmacological agents physical methods were used in only about a quarter of all hip reconstructions and abdominal or thoracic operations.

Physical methods are likely to be most attractive in circum- 